\title{
A STUDY ON CLINICAL PROFILE AND OUTCOME OF PATIENTS WITH ACUTE RESPIRATORY DISTRESS SYNDROME IN A TERTIARY CARE HOSPITAL IN NORTH EAST INDIA
}

\author{
Deepak Chaudhury¹, Jehbi Hasan², Subhankar Paul ${ }^{3}$, Ilias Ali ${ }^{4}$ \\ ${ }^{1}$ Assistant Professor, Department of Emergency Medicine, Gauhati Medical College and Hospital. \\ ${ }^{2}$ Senior Resident, Department of Emergency Medicine, Gauhati Medical College and Hospital. \\ ${ }^{3}$ Postgraduate Student, Department of Emergency Medicine, Gauhati Medical College and Hospital. \\ ${ }^{4}$ Professor and HOD, Department of Emergency Medicine, Gauhati Medical College and Hospital.
}

ABSTRACT
BACKGROUND
Acute respiratory distress syndrome (ARDS) is a life threatening condition in which respiratory failure occurs due to lung injury
caused by various aetiological factors. Acute hypoxemic respiratory failure as occurs in ARDS requires positive pressure
ventilation. ARDS is a major cause of morbidity and mortality; and it also leads to major expenditure in intensive care units.

\section{MATERIALS AND METHODS}

This is a prospective observational study conducted over a period of one year in Emergency/ICU to study various clinical profiles of ARDS patients. Adult patients who fulfilled the criteria for ARDS according to the Berlin Definition of 2012 were included in the study.

\section{RESULTS}

Clinical profiles of 44 ARDS patients were studied. There was predominance of male gender \& young age. The mortality in our study was $54.54 \%$. Non-survivors had significantly more incidence of severe ARDS \& sepsis as aetiology of ARDS. On discharge from the ICU, there was no major pulmonary or cardiovascular complications.

\section{CONCLUSION}

Despite lung protective ventilation, mortality and morbidity in ARDS is quite high worldwide. Therefore, high index of clinical suspicion is required to detect it early.

\section{KEYWORDS}

ARDS, Berlin Definition, Lung Protective Ventilation, Sepsis.

HOW TO CITE THIS ARTICLE: Chaudhury D, Hasan J, Paul S, et al. A study on clinical profile and outcome of patients with acute respiratory distress syndrome in a tertiary care hospital in Northeast India. J. Evolution Med. Dent. Sci. 2017;6(36):2943-2947, DOI: $10.14260 / \mathrm{Jemds} / 2017 / 634$

\section{BACKGROUND}

Acute respiratory distress syndrome (ARDS) was described for the first time by Ashbaugh and colleagues (1967). They described ARDS as the 'acute onset of tachypnoea, hypoxaemia and loss of compliance after a variety of stimuli'.(1) The term 'adult respiratory distress syndrome' was initially used to describe the condition but it was subsequently renamed as 'Acute Respiratory Distress Syndrome' because it may also occur in children.(2) However, it was not until 1994 that an International AmericanEuropean Consensus Conference (AECC) laid the foundations for the definition of ARDS(3) which was further modified in Berlin, 2011 which is presently accepted as a universal definition for ARDS.(4)

Acute respiratory distress syndrome (ARDS) is a life threatening respiratory failure due to direct or indirect lung injury caused by many aetiological factors. ${ }^{(5)}$ Clinical features

Financial or Other, Competing Interest: None.

Submission 27-03-2017, Peer Review 22-04-2017,

Acceptance 27-04-2017, Published 04-05-2017.

Corresponding Author:

Dr. Deepak Chaudhury,

Panjabari, Lakhimipath,

House No. 3, P. O. Khanapara,

Guwahati-781037, Assam.

E-mail: deepak9891chaudhury@gmail.com

DOI: $10.14260 /$ jemds $/ 2017 / 634$

\section{(c) $($ ) $\Theta$}

of ARDS are severe dyspnoea, tachypnoea, and hypoxaemia refractory to supplemental oxygen along with the clinical features of the initiating injury.(6) All patients should be assessed for an underlying cause (particularly pneumonia, sepsis, pancreatitis or transfusion related lung injury) and treated promptly. The pulmonary pathology of ALI/ARDS can be divided into acute and fibroproliferative phases ${ }^{(5)}$ which is characterised by diffuse alveolar damage, leakage from alveolar capillaries, and protein rich pulmonary oedema leading to poor lung compliance, severe hypoxaemia, and bilateral infiltrates on chest radiograph.

ARDS is characterised by severe acute hypoxaemic respiratory failure with increased work of breathing and decreased lung compliance, which together usually mandate mechanical ventilation.(4) The role of non-invasive ventilation in ARDS is contentious; there are no large definitive studies, and although some groups report encouraging results these are usually in patients with mild ARDS. NIV failure is common which is associated with more complications and mortality rates, possibly due to delayed intubation, high leaks, abdominal distension, etc.(7) The method and delivery of ventilatory support must consider both the pathophysiology of ARDS and ventilator-induced lung injury (VILI). The ARDS Network randomised 861 ALI patients from 75 ICUs to receive either a tidal volume (VT) of 6 or $12 \mathrm{~mL} / \mathrm{kg}$ predicted body weight. Mortality was reduced by $22 \%$, from $40 \%$ to $31 \%$, in the lower VT group. There was a strict FiO2 \& PEEP 
protocol, and patients were ventilated in assist-control mode to avoid excessive spontaneous VT.(8)

Lung-protective ventilation is still the key of better outcome in ARDS. Though in randomised trials, prone ventilation in severe ARDS, short-term use of neuromuscular blockade at initial stage of mechanical ventilation, and extracorporeal membrane oxygenation in ARDS with influenza pneumonia showed beneficial efficacy.(9-12) However, ARDS mortality still remains high. Therefore, early recognition of ARDS by identifying risk factors and the avoidance of aggravating factors during the patient's hospital stay can help decrease its development and progression. Our study therefore aims at studying the overall clinical profile of ARDS patients starting from ICU admission, undergoing mechanical ventilation to discharge or death, and comparing various parameters among survivors \& non-survivors.

\section{MATERIALS AND METHODS}

A single-centre prospective observational study was conducted involving the patients admitted in the Emergency/ICU under the Department of Emergency Medicine in Gauhati Medical College \& Hospital after obtaining institutional ethical committee clearance. Patients aged 18 years or elder, fulfilling the criteria of ARDS according to the Berlin definition, $2012^{4}$ were included in the study whereas patients of known COPD, bronchial asthma, active pulmonary TB, interstitial lung disease, congestive heart failure, chronic liver disease, chronic kidney disease, and patients with pregnancy were excluded from the study.

Primary outcome variable studied was mortality during ICU stay while time duration on mechanical ventilation, clinical parameters during discharge, etc were the secondary variables studied. Detailed history taking and physical examination were done for every patient at the time of admission to ICU along with relevant investigations viz ABG, Chest X-ray, ECG, haematological and biochemical examinations of blood and appropriate specimen cultures, etc. ABG \& Chest X-ray were done routinely every 24 hourly and as and when necessary till weaning from ventilator. Initial ventilator parameters like mode, FiO2, PEEP, peak inspiratory pressure, plateau pressure, tidal volume, respiratory rate were measured after 20 minutes of mechanical ventilation. Lung protective ventilation strategy as laid by ARDS Network protocol was followed for every patient on mechanical ventilation and parameters were noted accordingly. Daily SOFA scoring was done for every patient for signs of organ failure.

Results of numerical variables were reported as mean \pm SD and categorical variables were reported in frequency \& percentages. Student's $\mathrm{t}$ test or Kruskal-Wallis test was applied to test the significance while comparing numerical data \& Fisher exact test was applied for categorical data. All statistical analyses were done with SPSS 16.0 software.

\section{RESULTS}

After applying inclusion and exclusion criteria, clinical profiles of 44 ARDS patients were studied. There was Male predominance $(\mathrm{n}=28,64 \%$ ) (Fig-1), with male to female ratio 1.75:1.

The mean age in this study was $40.4 \pm 14.12$ years (Mean $\pm \mathrm{SD}$ ), with majority of the patients in relatively younger age group (Table 1).
Table 2 shows aetiological factors of ARDS in our study where non-pulmonary sepsis was the commonest cause $(n=13,29.5 \%)$ followed by direct lung injury by aspiration $(\mathrm{n}=10,22.7 \%)$

Mean time of onset of ARDS following exposure to a known clinical insult was $3.59 \pm 1.56$ days. Majority of the patients presented with breathlessness ( $\mathrm{n}=36,82 \%)$, fever $(n=29,66 \%)$ and altered sensorium $(n=28,63.6 \%)$.

Most of the patients fell into the category of Moderate ARDS $(100<\mathrm{PaO} 2 / \mathrm{FiO} 2<200)$ as shown in Table 4.

24 patients out of total 44 patients in our study died leading to a mortality rate of $54.5 \%$ (Figure 2). Comparison of various parameters between survivors \& non-survivors, showed that severe ARDS, sepsis as initial diagnosis were significantly associated with higher mortality.

Most of the survivors who were discharged from ICU had no residual cardiovascular/haematological/hepatic dysfunction or any pneumothorax following lung-protective ventilation (Table 6).

\begin{tabular}{|c|c|c|c|c|c|c|}
\hline $\begin{array}{c}\text { AGE } \\
\text { Groups } \\
\text { (Years) }\end{array}$ & $\mathbf{1 8 - 2 8}$ & $\mathbf{2 8 - 3 8}$ & $\mathbf{3 8 - 4 8}$ & $\mathbf{4 8 - 5 8}$ & $\mathbf{5 8 - 6 8}$ & $\mathbf{6 8 - 7 8}$ \\
\hline $\begin{array}{c}\text { No. of } \\
\text { Patients } \\
(\%)\end{array}$ & $\begin{array}{c}11 \\
(25 \%)\end{array}$ & $\begin{array}{c}8 \\
(18 \%)\end{array}$ & $\begin{array}{c}12 \\
(27.2 \%)\end{array}$ & $\begin{array}{c}7 \\
(16 \%)\end{array}$ & $\begin{array}{c}4 \\
(9 \%)\end{array}$ & $\begin{array}{c}2 \\
(4.5 \%)\end{array}$ \\
\hline
\end{tabular}

Table 1. Age-wise Distribution of Patients with ARDS

\begin{tabular}{|c|c|c|}
\hline \multicolumn{2}{|c|}{ Aetiological Factors } & $\mathbf{n}, \mathbf{\%}(\mathbf{n = 4 4 )}$ \\
\hline $\begin{array}{c}\text { Direct lung } \\
\text { injury }\end{array}$ & Aspiration & $\mathbf{1 0}(\mathbf{2 2 . 7 \% )}$ \\
\cline { 2 - 3 } & Pneumonia & $\mathbf{6 ( 1 3 . 6 \% )}$ \\
\cline { 2 - 3 } & Fat Embolism & $\mathbf{2 ( 4 . 5 \% )}$ \\
\hline \multirow{4}{*}{ Indirect causes } & Sepsis & $13(29.5 \%)$ \\
\cline { 2 - 3 } & Shock & $9(20.4 \%)$ \\
\cline { 2 - 3 } & Acute Pancreatitis & $5(11.3 \%)$ \\
\cline { 2 - 3 } & Malaria & $4(9 \%)$ \\
\cline { 2 - 3 } & Major Trauma & $3(7 \%)$ \\
\cline { 2 - 3 } & Anaphylaxis & $1(2.25 \%)$ \\
\cline { 2 - 3 } & Drug overdose & $1(2.25 \%)$ \\
\hline
\end{tabular}

Table 2. Direct \& Indirect Causes for of ARDS

\begin{tabular}{|c|c|}
\hline Signs and Symptoms & No. of Patients \\
\hline Fever & 29 \\
\hline Cough & 11 \\
\hline Breathlessness & 36 \\
\hline Haemoptysis & 03 \\
\hline Chest pain & 05 \\
\hline Cyanosis & 03 \\
\hline Pain abdomen & 18 \\
\hline Bilateral Pedal Oedema & 10 \\
\hline Ascites & 08 \\
\hline Altered sensorium & 28 \\
\hline Hypotension & 22 \\
\hline Tachypnoea & 43 \\
\hline Abnormal respiratory pattern & 26 \\
\hline Distended neck veins & 0 \\
\hline \multicolumn{2}{|c|}{ Admission } \\
\hline \multicolumn{2}{|c|}{ Shows Clinical Features of ARDS Patients on } \\
\hline \multicolumn{2}{|c|}{}
\end{tabular}




\begin{tabular}{|c|c|c|}
\hline Category of ARDS & No. of Patients & Percentage \\
\hline Mild & 05 & $11.3 \%$ \\
\hline Moderate & 21 & $47.7 \%$ \\
\hline Severe & 18 & $10.9 \%$ \\
\hline
\end{tabular}

\begin{tabular}{|c|c|c|c|}
\hline Parameters & $\begin{array}{c}\text { Survivors } \\
(\mathbf{n}=\mathbf{2 0})\end{array}$ & $\begin{array}{c}\text { Non-survivors } \\
(\mathbf{n = 2 4 )}\end{array}$ & $\begin{array}{c}\mathbf{P} \\
\text { Value }\end{array}$ \\
\hline Age (Mean \pm SD ) & $39.25 \pm 17.39$ & $41.3 \pm 11.45$ & 0.644 \\
\hline Gender, male (n, \%) & $12(27 \%)$ & $16(36 \%)$ & 0.5284 \\
\hline $\begin{array}{c}\text { Time of onset } \\
(\text { Mean } \pm \text { SD) }\end{array}$ & $3.45 \pm 0.359$ & $3.71 \pm 1.55$ & 0.5918 \\
\hline $\begin{array}{c}\text { Direct lung injury } \\
(\mathrm{n}, \%)\end{array}$ & $10(23 \%)$ & $7(16 \%)$ & 0.2176 \\
\hline $\begin{array}{c}\text { Sepsis as Initial } \\
\text { diagnosis }\end{array}$ & $3(15 \%)$ & $13(54.1 \%)$ & 0.0079 \\
\hline Severe ARDS (n, \%) & $3(15 \%)$ & $15(62.5 \%)$ & 0.0016 \\
\hline $\begin{array}{c}\text { Metabolic Acidosis } \\
(\mathrm{n}, \%)\end{array}$ & $4(20 \%)$ & $9(37.5 \%)$ & 0.1753 \\
\hline $\begin{array}{c}\text { Duration of MV in } \\
\text { DAYS (Mean } \pm \text { SD) }\end{array}$ & $9.2 \pm 2.04$ & $4.79 \pm 2.68$ & $<0.0001$ \\
\hline $\begin{array}{c}\text { ICU Stay Days } \\
\text { (Mean } \pm \text { SD) }\end{array}$ & $12.95 \pm 2.85$ & $4.8 \pm 2.7$ & $<0.0001$ \\
\hline \multicolumn{4}{|c|}{ Table 5. Comparison Between Various Parameters } \\
among Survivors \& Non-survivors \\
\hline
\end{tabular}

\begin{tabular}{|c|c|}
\hline Parameter & No. of Patients \\
\hline Requirement of supplemental oxygen & 06 \\
\hline GCS 14/15 & 07 \\
\hline Organ dysfunction & 03 \\
\hline Renal & 0 \\
\hline Cardiovascular & 0 \\
\hline Biliary & 0 \\
\hline Haematological & 0 \\
\hline Acid base imbalance & \\
\hline Persistent pulmonary infiltrates & 0 \\
involving & 0 \\
\hline 4 quadrants & 4 \\
\hline 3 quadrants & 5 \\
\hline 2 quadrants & 0 \\
\hline 1 quadrant & 0 \\
\hline Pneumothorax & 0 \\
\hline Pneumomediastinum & \\
\hline Subcutaneous emphysema & at Discharge from ICU Survivors \\
\hline \multicolumn{2}{|c|}{} \\
\hline
\end{tabular}

\section{Fig 1: Gender wise distribution of} ARDS

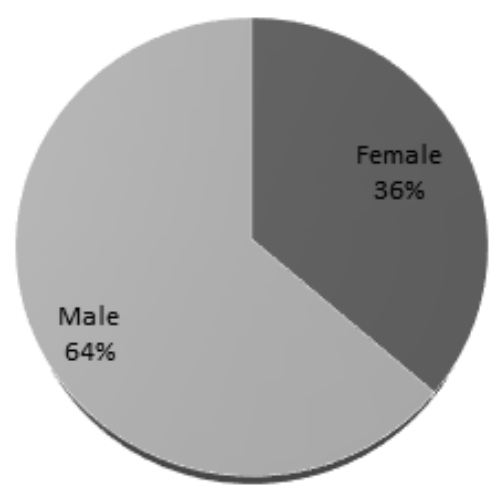

Figure 1. Pie Diagram Showing Gender Distribution of ARDS Patients in our Study

\section{Fig 2 : Mortality in ARDS patients}

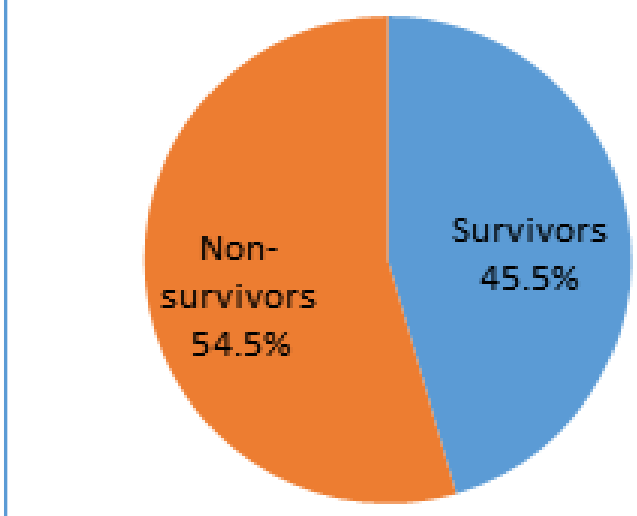

\section{Figure 2. Pie Diagram Showing Mortality in ARDS Patients}

\section{DISCUSSION}

A prospective study by Heffernan et al(13) showed that females were more likely to develop ARDS (35\% versus $25 \%$, $\mathrm{p}=0.02$ ) whereas our study exhibited a male predominance. Maximum number of patients belonged to the age group of $38-48$ years (27.2\%) followed by $25 \%$ in the age group of 18 28 years. Only about $30 \%$ patients were more than 48 years of age. The mean age in this study was $40.4 \pm 14.12$ years (Mean \pm SD). In a study by Bhadade et al,(14) in Maharashtra, the mean age of ARDS patients was 37.9 years. Singh et al(15) found the mean age in ARDS patients in their study to be 44.8 \pm 15.5 years. It appears that ARDS is commonly seen in younger age group.

In our study, commonest aetiological factor for developing ARDS was non-pulmonary sepsis (29.5\%), followed by aspiration (22.7\%) \& shock (20.4\%) which was similar to the observation by Gajic et al.(6) However, Study by Rubenfeld et al(16) showed most common cause was severe sepsis with pulmonary aetiology (46\%) and Agarwal et al(17) also showed pneumonia to be the commonest aetiology for ARDS.

In this study, out of 44 patients, severe ARDS occurred in 18 patients (40.9\%), moderate ARDS in 21 patients $(47.7 \%)$ and mild ARDS in 5 patients (11.3\%). In a study by Thille et al,(18) incidence of mild ARDS was $14 \%$, moderate $40 \%$ and severe $46 \%$. The ALIVE study group(19) reported the incidence of mild ARDS to be $30 \%$ at presentation but half of them later developed moderate or severe ARDS. But mild ARDS being a frequently underdiagnosed condition the incidence of three categories of ARDS only represents an estimate.

The mortality in our study was $54.54 \%$. The study was Esteban et al(20) found the overall mortality rate in the intensive care unit to be $30.7 \%$ whereas the mortality was $52 \%$ in patients who received ventilation because of ARDS. In studies by Agarwal et al(17) \& Rubenfeld et al,(16) the hospital mortality rate for ARDS was $47.8 \%$ \& $41.1 \%$ respectively. Recent studies show a decreasing trend in mortality from ARDS patients which might be attributed to the widespread adoption of lung protective mechanical ventilation strategies in ARDS patients. The ARMA trial of ARDS Net group showed 
mortality of $21 \%$ in those with lung protective mechanical ventilation vs. $40 \%$ in those with conventional ventilation. ${ }^{(8)}$ Erickson et al(21) observed that crude mortality in ARDS was 35\% in 1996-1997 and declined during each subsequent time period to a low of $26 \%$ in 2004-05. In a recent prospective, multicentre observational study by Villar et al,(22) it was seen that despite the use of lung protective ventilation, the ICU mortality of ARDS patients was still more than $40 \%$.

16 of the 28 male patients (57\%) and 8 of the 16 female (50\%) did not survive, and this gender difference was not statistically significant $(\mathrm{p}=0.756)$. The study by Luhr et al (23) in 1231 patients with acute respiratory failure and ARDS also demonstrated that gender was not independently associated with mortality. Bhadade et al(14) found mortality in females to be higher than males (73\% vs. 51\%) but the difference was not statistically significant $(\mathrm{p}=0.23)$.

The mean age of the survivors was $39.25 \pm 17.39$ years (mean \pm SD) and that of non-survivors was $41.3 \pm 11.45$ years (mean \pm SD). Although the mean age was more in nonsurvivors, the difference was not statistically significant ( $\mathrm{p}=$ 0.644) as also observed by Singh et al.(15) Some studies have shown increased risk of ARDS and increased mortality too in the elderly age group. In a study by Rubenfeld,(16) it was seen that mortality increased with age from $24 \%$ for patients 15 through 19 years of age to $60 \%$ for patients 85 years of age or older $(\mathrm{P}<0.001)$. Suchyta et al found significant increase in mortality in ARDS with age more than 65 years.

In this study, it was also found that severe ARDS patients were more likely to die than mild or moderate ARDS patients $(\mathrm{p}<0.0002)$ which was also reflected in studies by Rubenfeld et al.(16) The ARDS task force conducted a meta-analysis of 7 clinical trials and prepared a draft of the Berlin definition in which they observed that the mortality in mild ARDS was $27 \%$ (95\% CI 24\% - 30\%), in moderate ARDS 32\% (95\% CI $29 \%-34 \%$ ) and in severe ARDS 45\% ( $95 \%$ CI 42\%-48\%) and the difference was statistically significant ( $\mathrm{p}<0.001)$.(4)

In this study, it was seen that 13 patients out of 44 (29.5\%) presented with metabolic acidosis on admission to ICU. Though it was statistically not significant $(\mathrm{p}=0.1753)$, Metabolic acidosis has been found to correlate with increased mortality in some studies on ARDS. Bru-Buisson et al(19) observed that $\mathrm{pH}<7.3$ was associated with mortality in ARDS. Bhadade et al(14) found that acidosis is an independent factor associated with mortality.

Mean duration of Mechanical ventilation \& ICU stay were significantly high in survivors $(9.2 \pm 2.04 \& 12.95 \pm 2.85$ days) vs. non-survivors ( $4.79 \pm 2.68 \& 4.8 \pm 2.7$ ) possibly reflecting the early mortality of the non-survivors. However, Rios et al(24) in 2009 observed that in survivors of ARDS mechanical ventilation was required for an average of 11 days (6-19 days). Bhadade et al(14) found mean duration of survival of ARDS patients was 4.55 days.

The mean duration of survival was $4.8 \pm 2.7$ days in this study. The mean duration of survival was 4.55 days in the study by Bhadade et al.(14) Incidence of barotraumas viz. pneumothorax, pneumomediastinum, subcutaneous emphysema was zero in this study. At the time of discharge from the ICU, 7 patients (35\%) had GCS 14 and 3 patients (15\%) had persistent renal dysfunction. 6 (30\%) of the 20 survivors were still in need of supplemental oxygen via face mask for maintaining oxygenation at the time of discharge from ICU. None of the survivors had hypotension or acid-base imbalance at the time of discharge. At the time of discharge from ICU, 9 (45\%) patients had persistent pulmonary infiltrates involving either one or two quadrants on frontal chest radiograph.

\section{CONCLUSION}

ARDS is characterised by progressive and refractory hypoxaemia arising from diverse direct or indirect injuries to lung. Despite the progress in understanding of its pathophysiology, aggressive treatment strategies and lung protective ventilation, mortality and morbidity remain quite high. Therefore, keeping high index of suspicion based on the clinical pictures of the patients and early detection help to halt its progress.

\section{REFERENCES}

[1] Ashbaugh DG, Bigelow DB, Petty TL, et al. Acute respiratory distress in adults. The Lancet 1967;2(7511):319-23.

[2] Petty TL, Ashbaugh DG. The adult respiratory distress syndrome: clinical features, factors influencing prognosis and principles of management. Chest 1971;60(3):233-9.

[3] Bernard GR, Artigas A, Brigham KL, et al. The American-European consensus conference on ARDS. Definitions, mechanisms, relevant outcomes, and clinical trial coordination. American journal of respiratory and critical care medicine 1994;149(3 Pt 1):818-24.

[4] ARDS Definition Task Force, Ranieri VM, Rubenfeld $\mathrm{GD}$, et al. Acute respiratory distress syndrome: the berlin definition. JAMA 2012;307(23):2526-33.

[5] Flick MR, Matthay M. Pulmonary edema and acute lung injury. Textbook of respiratory medicine. $2^{\text {nd }}$ edn. Philadelphia: Saunders 1994:1725-62.

[6] Gajic 0, Dabbagh O, Park PK, et al. Early identification of patients at risk of acute lung injury: evaluation of lung injury prediction score in a multicenter cohort study. American journal of respiratory and critical care medicine 2011;183(4):462-70.

[7] Nava S, Schreiber A, Domenighetti G. Noninvasive ventilation for patients with acute lung injury or acute respiratory distress syndrome. Respiratory care 2011;56(10):1583-8.

[8] Acute Respiratory Distress Syndrome Network, Brower RG, Matthay MA, et al. Ventilation with lower tidal volumes as compared with traditional tidal volumes for acute lung injury and the acute respiratory distress syndrome. N Engl J Med 2000;342(18):1301-8.

[9] Guérin C, Reignier J, Richard JC, et al. Prone positioning in severe acute respiratory distress syndrome. New England Journal of Medicine 2013;368(23):2159-68.

[10] Park SY, Kim HJ, Yoo KH, et al. The efficacy and safety of prone positioning in adults patients with acute respiratory distress syndrome: a meta-analysis of randomized controlled trials. Journal of thoracic disease 2015;7(3):356-67. 
[11] Papazian L, Forel JM, Gacouin A, et al. Neuromuscular blockers in early acute respiratory distress syndrome. The New England journal of medicine 2010;363(12):1107-16.

[12] Noah MA, Peek GJ, Finney SJ, et al. Referral to an extracorporeal membrane oxygenation center and mortality among patients with severe 2009 influenza A(H1N1). JAMA 2011;306(15):1659-68.

[13] Heffernan DS, Dossett LA, Lightfoot MA, et al Gender and acute respiratory distress syndrome in critically injured adults: a prospective study. The Journal of trauma 2011;71(4):878-85.

[14] Bhadade RR, De Souza R, Harde MJ, et al. Clinical characteristics and outcomes of patients with acute lung injury and ARDS. Journal of postgraduate medicine 2011;57(4):286-90.

[15] Singh G, Gladdy G, Chandy TT, et al. Incidence and outcome of acute lung injury and acute respiratory distress syndrome in the surgical intensive care unit. Indian Journal of Critical Care Medicine 2014;18(10):659-65.

[16] Rubenfeld GD, Caldwell E, Peabody E, et al. Incidence and outcomes of acute lung injury. New England Journal of Medicine 2005;353(16):1685-93.

[17] Agarwal R, Aggarwal AN, Gupta D, et al. Etiology and outcomes of pulmonary and extrapulmonary acute lung injury/ARDS in a respiratory ICU in North India. Chest Journal 2006;130(3):724-9.
[18] Thille AW, Esteban A, Fernández-Segoviano P, et al. Comparison of the Berlin definition for acute respiratory distress syndrome with autopsy. American journal of respiratory and critical care medicine 2013;187(7):761-7.

[19] Brun-Buisson C, Minelli C, Bertolini G, et al. Epidemiology and outcome of acute lung injury in European intensive care units. Results from the ALIVE study. Intensive care medicine 2004;30(1):51-61.

[20] Esteban A, Anzueto A, Frutos F, et al. Characteristics and outcomes in adult patients receiving mechanical ventilation: a 28-day international study. JAMA 2002;287(3):345-55.

[21] Erickson SE, Martin GS, Davis JL, et al. Recent trends in acute lung injury mortality: 1996-2005. Critical care medicine 2009;37(5):1574-9.

[22] Villar J, Blanco J, Añón JM, et al. The ALIEN study: incidence and outcome of acute respiratory distress syndrome in the era of lung protective ventilation. Intensive care medicine 2011;37(12):1932-41.

[23] Luhr OR, Antonsen K, Karlsson M, et al. Incidence and mortality after acute respiratory failure and acute respiratory distress syndrome in Sweden, Denmark, and Iceland. The ARF Study Group. American journal of respiratory and critical care medicine 1999;159(6):1849-61.

[24] Ríos FG, Estenssoro E, Villarejo F, et al. Lung function and organ dysfunctions in 178 patients requiring mechanical ventilation during the 2009 influenza A (H1N1) pandemic. Critical care 2011;15(4):R201. 